\title{
Reading strategies and prior knowledge in learning from hypertext
}

\author{
LADISLAO SALMERÓN \\ University of Granada, Granada, Spain \\ WALTER KINTSCH \\ University of Colorado, Boulder, Colorado \\ and \\ JOSÉ J. CAÑAS \\ University of Granada, Granada, Spain
}

\begin{abstract}
In two experiments, we identified two main strategies followed by hypertext readers in selecting their reading orders. The first consisted in selecting the text semantically related to the previously read section (coherence strategy), and the second in choosing the most interesting text, delaying reading of less interesting sections (interest strategy). Comprehension data revealed that these strategies affected learning differently as a function of the reader's prior knowledge. For low-knowledge readers, the coherence strategy supported better learning of the content. This effect seems to rely on the improvement of reading order coherence induced by this strategy. By contrast, for intermediateknowledge readers the coherence and the interest strategies benefited comprehension equally. In both cases, learning was supported through the active processing induced by these strategies. Discussion focuses on resolving inconsistencies in the literature concerning whether or not hypertext supports better comprehension than does traditional linear texts.
\end{abstract}

Comprehending a text in hypertext format requires the same cognitive processes involved in reading a traditional linear text. However, hypertext demands an additional cognitive process that is minimized when a linear text is being read: the selection of the reading order of the text sections (but see Dillon, 1991; Goldman \& Saul, 1990; Goldman, Saul, \& Coté, 1995, for the study of order selection in linear text). Hypertext readers follow different strategies to select reading order, which can affect comprehension (Anderson-Inman \& Horney, 1994; Barab, Bowdish, \& Lawless, 1997; Barab, Bowdish, Young, \& Owen, 1996; Barab, Fajen, Kulikowich, \& Young, 1996; Barab, Young, \& Wang, 1999; Britt, Rouet, \& Perfetti, 1996; Foltz, 1996; Horney \& Anderson-Inman, 1994; Lawless \& Kulikowich, 1996, 1998; Lawless, Mills, \& Brown, 2002; Niederhauser, Reynolds, Salmen, \& Skolmoski, 2000; Rouet, Favart, Britt, \& Perfetti, 1997; Salmerón, Cañas, Kintsch, \& Fajardo, in press). However, until now there has been no agreement in the literature regarding the strategies that

This research was conducted thanks to funding from Fulbright Commission Spain and the Spanish Ministerio de Educación to the first author. We thank Danielle McNamara and an anonymous reviewer for insightful comments on an early version of the manuscript. Correspondence may be sent to L. Salmerón, Department of Experimental Psychology, University of Granada, Campus de Cartuja, s/n 18071 Granada, Spain (e-mail: lalo@ugr.es).

Note-This article was accepted by the previous editorial team, when Colin M. MacLeod was Editor. hypertext readers follow when their main purpose is to comprehend a text (Unz \& Hesse, 1999). The identification and analysis of these strategies would allow the determination of how order selection affects comprehension and whether or not the use of this feature could result in improved learning in comparison with linear texts.

Two main approaches have been used to describe hypertext reading strategies: the analysis of the navigational path and the description of the criteria followed in the selection of reading order. The first approach consists in the identification of similar groups of navigational paths through the use of a multidimensional scaling technique. Research in this approach starts without any hypothesis about which strategies people might use, and it is the multidimensional scaling technique that allows the groups whose strategies the researcher will later interpret to be identified. One of the most extended classifications is that put forth by Lawless and Kulikowich (1996, 1998; see also Anderson-Inman \& Horney, 1994; Barab et al., 1997), which identified three main navigational groups: knowledge seekers, feature explorers, and apathetic hypertext users. Knowledge seekers spend most of their reading time on content-related documents, whereas feature explorers concentrate on the special features of the hypertext (e.g., images, videos, maps). Finally, apathetic users spend short intervals of time on content-related documents and seem to follow a random reading order. However, later experiments describe other navigational groups, suggesting that the navigational path found in an experiment often depends on the particular hypertext used (in terms of content structure and additional 
features) or the particular technique of using it (e.g., number of groups in a cluster analysis). This makes it difficult to compare results across experiments.

The second approach for assessing reading strategies describes theoretically the general criteria followed by participants when selecting reading order. This has been accomplished by analyzing cognitively relevant aspects of the reading order (e.g., text coherence between paragraphs transited) or by using the think-aloud methodology (Foltz, 1996). This approach overcomes the limits of the grouping of the navigational path because it allows for a fair comparison between experiments and makes it possible to relate the strategies to cognitive models of comprehension. Following this approach, Foltz identified the coherence strategy, which consists in the selection of the reading order that builds a thematically coherent reading sequence. The description of this strategy is inspired by the strategy competition model of Goldman and Saul (1990), which states that readers try to establish global discourse coherence while progressing through a text. If at one point the reader detects a gap in his or her comprehension of the content, he or she would move through the text looking for the necessary information in order to fill this gap. However, as some previous research reveals, the coherence strategy is not the only one followed by hypertext readers. For example, Ainley, Hidi, and Berndorff (2002) presented high-school students with four texts on different topics that could be read in a self-selected order. They concluded that some participants first selected the sections they considered most interesting, thus delaying the selection of the less interesting ones.

In the present work, we follow the second approach in order to identify the main reading strategies used by hypertext readers and to explain their effects on comprehension in relation to general theories of text comprehension. We consider that the first step was necessary to empirically identify the coherence and interest strategies, because the prior literature is not sufficiently conclusive. Regarding the coherence strategy, it has been found that the coherence (i.e., semantic relation) between the transited sections is positively correlated to learning outcomes (Foltz, 1996). However, this effect does not necessarily constitute evidence that hypertext readers look actively for coherence, because one could just passively follow the structure of the hypertext content in order to construct a highly coherent reading order (Salmerón et al., 2005). Regarding the interest strategy, it has been proposed that the interest induced by a section title is positively related to the order in which that title will be selected (Ainley et al., 2002). However, the authors reported that approximately $50 \%$ of their participants simply read the text following the order in which it was presented on the screen, so they were not able to correlate interest in the title with selection order (p. 550).

In order to empirically validate these strategies, we conducted two pilot experiments in which we asked participants to describe, in their own words, the main criteria they followed in moving through the hypertext while trying to comprehend a text. An expository text divided into 24 pages was used in both experiments. In the first, an overview of the content was provided from which the readers could access any of the documents; in the second, no overview was used. A total of 61 participants participated in the study (30 in Experiment 1 and 31 in Experiment 2). Although most of the participants (62\%) declared that they did not follow any strategy, from the affirmative responses we identified three criteria: coherence, whereby the link most directly related to the one previously read is selected (25\%); interest, whereby the links considered most interesting are selected (11\%); and ease, whereby the links considered easiest are selected (2\%). However, these percentages should be interpreted cautiously. The selection of a particular strategy for comprehending a text could depend on several features of both the hypertext and the reader. In addition, the method employed in these pilot experiments of simply asking a general question could have magnified the number of negative responses (i.e., no strategy followed) obtained. Nevertheless, a fair interpretation of these results calls for identifying the two reading strategies followed by hypertext readers suggested by previous research: coherence (e.g., Foltz, 1996) and interest (e.g., Ainley et al., 2002). Therefore, in the remainder of this article we will analyze these two strategies and their relations to text comprehension.

\section{Reading Strategies and Text Comprehension}

To explore the effects of reading strategy on comprehension in hypertext, we begin with the constructionintegration (C-I) model of text comprehension (W. Kintsch, 1988, 1998; van Dijk \& Kintsch, 1983). The C-I model conceives of comprehension as a process of relating the ideas of a text in a coherent representation. This is accomplished in two phases: In the construction phase, a network of interconnected propositions is generated from the text, and in the integration phase the highly interconnected links are identified by a spreading activation process. Information from the text is processed in serial cycles. Therefore, in order to maintain coherence between segments, the one or two nodes most highly weighted at the end of a cycle are stored in working memory to be available in the next processing cycle. The model distinguishes between two of the mental representations that a reader forms from the text: the text base, a hierarchical propositional representation of the information within the text; and the situation model, which integrates that information with the reader's prior knowledge. According to the $\mathrm{C}-\mathrm{I}$ model, many factors contribute to text comprehension, but coherence and prior knowledge are the main ones. Text coherence refers to the extent to which a reader is able to understand the relations between ideas in a text and is usually related to an increase in comprehension (Britton \& Gülgöz, 1991).

Different reading strategies induce readers to focus on different aspects of the text, which could be critical in determining the kind of interconnections established within the information read. This relation between reading strategies and comprehension has been reported exten- 
sively in the literature (Chi, Bassok, Lewis, Reimann, \& Glaser, 1989; Chi, De Leeuw, Chiu, \& LaVancher, 1994; Magliano, Trabasso, \& Graesser, 1999; McNamara, 2004; McNamara \& Scott, 1999; Pressley, Symons, McDaniel, Snyder, \& Turnure, 1988; Trabasso \& Magliano, 1996; Wagner \& Sternberg, 1987). There is no reason to argue that this relation, found in the literature of linear text comprehension, does not hold for hypertext comprehension as well. However, in the study of the influence of reading strategies on hypertext, an additional feature needs to be considered: Reading strategies determine the order in which the text is read, and this could affect its comprehension (Danner, 1976; W. Kintsch \& Yarbrough, 1982; Lodewijks, 1982; Mayer, 1976; Schnotz, 1982, 1984, 1993). Reading order itself plays an important role in comprehension because it can influence the process of relating text ideas. For example, a text written following a coherent scheme (e.g., the temporal sequence of the events) can become less coherent if read in a random order. In sum, we propose that reading strategies in hypertext could affect comprehension in two different ways: by a strategic influence associated with the reading strategy followed by the reader, and by a text-induced influence related to the changes in text order coherence (Salmerón et al., 2005). Although there is extensive work supporting each of these influences in isolation, in hypertext both act conjointly in determining the learning outcome of the reader. Following on this distinction, we will explore how the coherence and interest strategies affect comprehension in hypertext according to the $\mathrm{C}-\mathrm{I}$ model. In addition, because the model stresses the role of prior knowledge in comprehension, we will consider this variable in our exposition.

\section{Hypertext Reading Strategies and Prior Knowledge}

We will focus first on the coherence strategy. This strategy involves selecting nodes semantically related to the previously read nodes in order to establish a coherent reading order of the different documents (Foltz, 1996). We will explore both the text-induced and strategic influences, and their interactions with prior knowledge. Considering the text-induced influence of reading order, the C-I model predicts that this strategy would facilitate the process of relating important ideas in the text. By selecting a semantically related text, a hypertext reader would be able to maintain active the relevant propositions of the document read in order to link them to the important propositions in the next document (see, e.g., Budd, Whitney, \& Turley, 1995). Otherwise, as the distance between two related pieces of information increases, the relevant propositions read first will be deactivated, and it will be harder to link them once the related propositions are read. This is the same process by which text coherence improves comprehension. However, this relation between coherence and comprehension depends on the prior knowledge of the reader (McNamara, 2001; McNamara, E. Kintsch, Songer, \& W. Kintsch, 1996; McNamara \& W. Kintsch, 1996). Low-knowledge readers benefit more at the situ- ation model level from a high-coherence text, whereas high-knowledge readers learn more from a low-coherence text. The explanation for this effect is that low-knowledge readers cannot fill in gaps in the incoherent text without explicit guidance about relationships among text ideas; on the other hand, expert readers who are overguided will not actively use their own prior knowledge to form the situation model of the text. In the field of hypertext comprehension, Salmerón et al. (2005) found this effect of knowledge and coherence in hypertext when they compared low- and high-coherence reading orders. The coherence of the reading order was measured as the semantic overlap between the content of two transited nodes (Foltz, Kintsch, \& Landauer, 1998). Therefore, it can be concluded that the reading order inherently followed in a hypertext has coherence properties that can affect comprehension as well as other traditional features of the text that are considered to affect coherence (Charney, 1994; Fritz, 1999). According to these results, it could be argued that the coherence strategy would improve comprehension in hypertext mainly for low-knowledge readers but not for those with high prior knowledge. However, taking into account the possible strategic effects, the C-I model predicts that readers with prior knowledge would actively process the text in order to select the coherent order, overcoming the shallow processing induced by a high-coherence text (E. Kintsch \& W. Kintsch, 1995; McNamara, 2001). E. Kintsch and W. Kintsch asked participants reading a low- or a highcoherence text to comment on their understanding after every sentence of the text. In this case, the difference for high-knowledge participants found in other works (McNamara et al., 1996; McNamara \& W. Kintsch, 1996) disappeared. Therefore, considering both the text-induced and strategic influences, we could conclude that the coherence strategy would be beneficial for both readers with prior knowledge and those without it (see Table 1).

We will now analyze the interest strategy, which consists in first selecting those texts considered more interesting to the reader. Interest elicited by a hypertext node title can be individual or situational in nature (Ainley et al., 2002). Whereas individual interest refers to the reader's affinity for some stimulus or event, situational interest relates to a temporary emotional state elicited by some aspects of the situation or the text (Hidi, 2001). Although the specific contribution of each factor to topic interest is still an open question, research emphasizes the role of individual interest as the permanent source of interest during reading. By contrast, situational interest is limited to the feature that aroused that interest (e.g., the title of a particular link)

Table 1

Expected Effects of Reading Strategies as a Function of Prior Knowledge and Type of Influence

\begin{tabular}{|c|c|c|c|c|}
\hline \multirow[b]{2}{*}{ Strategy } & \multicolumn{2}{|c|}{ Low Knowledge } & \multicolumn{2}{|c|}{ Intermediate Knowledge } \\
\hline & Text Induced & Strategic & Text Induced & Strategic \\
\hline Coherence & + & & - & + \\
\hline Interest & - & - & + & + \\
\hline
\end{tabular}


and is not necessarily maintained during the entire reading session (Ainley et al., 2002). Therefore, it should be noted that the interest strategy can be completely defined only on an individual basis (i.e., considering the particular individual interests of each reader) whereas the coherence strategy can be defined independently of the reader.

With regard to the text-induced effects of the interest strategy, the C-I model suggests that this strategy could hamper comprehension for low-knowledge readers because a selection not based on the semantic relation of the text would result in coherence breaks in reading order. ${ }^{1}$ For the same reason, it could be beneficial for readers with high prior knowledge. The conclusion regarding possible strategic influences points in the same direction. Numerous works in the literature show that interest in a text can enhance its comprehension (for a recent review, see Hidi, 2001). A possible explanation for this effect is that interest automatically provides attentional resources to the learning process that otherwise would need to be allocated in a controlled way (Hidi, 1990, 1995; McDaniel, Waddill, Finstad, \& Bourg, 2000). In addition, there is strong evidence that text interest could depend on the prior knowledge of the reader (Alexander, Jetton, \& Kulikowich, 1995; Alexander, Kulikowich, \& Schulze, 1994; Garner, Alexander, Gillingham, Kulikowich, \& Brown, 1991; Garner \& Gillingham, 1991; W. Kintsch, 1980; Wade, Buxton, \& Kelly, 1999; Walker, 1981). W. Kintsch (1980), for example, proposed that this relation takes the form of an inverted U-shaped curve: At one extreme, low-knowledge readers can find a new text incomprehensible and thus quite boring. At the other extreme, high-knowledge readers can find a text redundant and therefore without interest. It is between these extremes that a text can become interesting: For intermediate-knowledge readers, a text is not incomprehensible but still would present new information that can attract interest. This relation holds for processing too. Whereas uninterested low- and high-knowledge readers could engage in superficial processing and shallow confirmatory processing, respectively, interested intermediateknowledge readers could use their knowledge to construct a more complete representation of the text (Garner \& Gillingham, 1991).

Other proposals in the literature suggest a linear relation between interest and prior knowledge (Tobias, 1994). In any case, more important for our present purpose is to stress that interest can be beneficial for readers with some prior knowledge, but not for low-knowledge readers. In other words, low-knowledge readers would benefit more from the coherence strategy than from the interest strategy. Research on strategy training supports this prediction (Meyer \& Poon, 2001). Meyer and Poon found that low-knowledge readers instructed to develop a strategy for increasing text interest obtained lower learning scores than those who used a strategy intended to focus attention on the structural features of a text. In the field of hypertext comprehension, previous research has shown null effects of interest on text recall (Lawless, Brown, Mills, \& Mayall, 2003; Lawless \& Kulikowich, 1998). In two experiments,
Lawless et al. found that neither individual nor situational interest measured by a questionnaire was correlated with users of three navigational strategies (knowledge seekers, feature explorers, and apathetic users; see the discussion above) or with text recall. Unfortunately, the results were not reported for groups differing in prior knowledge, so we cannot conclude that the null effect held for both lowand intermediate-knowledge readers. In conclusion, considering both text-induced and strategic influences, results in the literature suggest that the interest strategy could be beneficial for readers with prior knowledge, but not for low-knowledge readers.

According to these results, an interaction could be expected between prior knowledge (low vs. intermediate) ${ }^{2}$ and strategy (coherence vs. interest) in hypertext comprehension (see Table 1): Low-knowledge readers learn more from the coherence strategy, whereas intermediateknowledge readers learn independently of the strategy followed. We tested these predictions in two experiments in which participants had to read an expository text in a particular hypertext that allowed us to isolate the order selection process (see the Materials section of Experiment 1). In Experiment 1, we encouraged the participants to read the sections in an order of their own choosing and analyzed their strategies a posteriori. In Experiment 2, we instructed the participants to read the text following a particular strategy (coherence or interest).

\section{EXPERIMENT 1}

The experimental hypotheses were as follows: (1) Participants with no prior knowledge learn more at the situation model level when following the coherence strategy than when following the interest strategy and (2) participants with prior knowledge learn equally at the situation model level, independent of which of these two strategies was used.

\section{Method}

\section{Participants}

Seventy-one University of Colorado undergraduates participated for class credit.

\section{Materials}

Hypertext. An expository text on atmospheric pollution was adapted for use in hypertext format. The text was 4,033 words long (including section titles) and was divided into 27 sections, or hypertext nodes. The structure of the text consisted of four main sections (Ozone Depletion, Greenhouse Effect, Air Pollution, and International Concern About Atmospheric Pollution). The text, which was at Flesh-Kincaid Grade Level 12, scored 34.6 in readability on the Flesch Reading Ease scale. Special care was taken to ensure that each node title represented its content as clearly as possible. For that purpose, node titles were written following a special procedure for analyzing the macrostructure of the text using latent semantic analysis (LSA; W. Kintsch, 2002). For each node, every sentence was compared with every other sentence using the matrix comparison analysis (i.e., a document-to-document test) and a corpus containing encyclopedia texts. The sentence with the highest sum of cosines was selected as the central sentence of the text. Every phrase of each central sentence was compared to the whole text on the node. The 
phrase with the highest cosine was chosen as the central idea of the text and was used as the title for that particular node. In some cases, the central phrase had to be slightly rewritten in order to accommodate it to title style. For example, the central phrase The seasonal ozone depletion has been severe was rewritten as the title "The Severe Seasonal Ozone Depletion."

A hypertext was constructed in order to isolate the link selection process. The contents of all the nodes were presented one at a time on the screen. After the participants finished reading each node, they could choose between only the two nodes with the highest and the lowest coherence with the previously read text. Coherence between texts was computed by comparing LSA cosines for the node just read with those of the remaining unread nodes (the whole text of each node was used for the matrix comparison analysis, a documentto-document test). LSA cosines provide a measure of the degree of argument overlap between texts, which is assumed to reflect the level of coherence between texts (Foltz et al., 1998). The two nodes were selected automatically by choosing the ones with the highest and the lowest LSA cosines. The links were presented one below the other. The positions of the high- and low-coherence links were randomized across selections. The participants were not aware of the distinction between the links. Each node was presented only once and could not be reread. For example, after reading the section entitled "Sources of Air Pollutant Emissions," the participants could be presented with a high-related section such as "Ground-Level Ozone in Metropolitan Cities" (LSA cosine 0.73) and a low-related section such as "Effects of Climate Change on Agriculture" (LSA cosine 0.22). In this case, the participant could use the information provided on the section read first, which described ground-level ozone as an air pollutant, to select the highly related node (for another example of the link selection process, see note 1 ).

It should be noted that the procedure used here allowed us to accurately identify when a reader had followed the coherence strategy by analyzing the number of times the reader selected the highcoherence link. However, this logic did not apply to the interest strategy because, as discussed in the introduction, topic interest depends mainly on the reader's preferences and therefore is not suitable for a generic procedure. For this reason, we relied on two different methods used in previous research for identifying when a reader had followed the interest strategy: retrospective debriefing methodology (Experiment 1) and strategy instruction (Experiment 2). Therefore, our method for assessing interest was independent of our method for identifying the coherence strategy. To put it in other words, we were able to identify whether or not a participant had selected a node on the basis of the interest criterion regardless of whether this node represented the highest or the lowest order coherence.

Prior knowledge questions. The participants were given a pretest of eight multiple-choice questions to determine individual differences in domain knowledge prior to the reading phase. The test assessed general knowledge of the topic "atmosphere pollution" rather than information specific to the text itself. Chance performance was at 33\%. Samples of the prior knowledge questions and of the other types of questions are provided in the Appendix.

Inference questions. We created 10 multiple-choice inference questions that required the participant to think about information located in at least two different nodes. Thus, this task was intended to assess situation model comprehension. Chance performance was at $33 \%$.

Relatedness judgment task. The participants were given a list of the 14 most important concepts in the text and instructed to rate the degree of relatedness of pairs of concepts. (The combination of all concepts resulted in 91 pairs.) The participants had to respond using a scale from 1 (high related) to 6 (low related). A PhD in atmospheric science provided expert ratings after reading the original text. We used these scores to compare the participants' solutions with that of an expert. The final score was obtained by applying the Pathfinder algorithm (Schvaneveldt, 1990) to each matrix using $r=\infty$ and $q=n-1$ and then comparing the resulting Pathfinder network to that of the expert. Pathfinder is a graph theoretic technique that derives network structures from proximity data. This algorithm provides a measure of the similarity $(C)$ between two networks. This value reflects the degree to which the same node in the two graphs is surrounded by similar sets of nodes. A $C$ value of 0 corresponds to two complementary graphs, and a value of 1 corresponds to equal graphs (see Dearholt \& Schvaneveldt, 1990, for a detailed discussion of the Pathfinder algorithm; see Acton, Johnson, \& Goldsmith, 1994, and Goldsmith, Johnson, \& Acton, 1991, for its use as a tool for assessing learning). The relatedness judgment task has been used successfully to assess situation model comprehension (see, e.g., Britton \& Gülgöz, 1991).

Text-based questions. We constructed a test consisting of 22 multiple-choice questions for which the question and the answer appeared in a single node and did not require the reader to infer information. Each question referred to the content of a different node. Chance performance was established at $33 \%$.

\section{Procedure}

The participants first underwent a pretest of 8 multiple-choice questions to assess their domain knowledge. They were then instructed on how to use the hypertext and asked to read the text without a time limit. The instructions stressed that the participants had to read the text carefully in order to answer a series of questions about it. Emphasis was placed on explaining that they could choose only the order in which to read the sections, but not which sections to read (the program would stop only after all the nodes had been presented). The reading procedure was as follows: First, the participants were presented with an introductory node with an overall description of the text. After reading a section, they had to click on a link at the bottom of the screen to announce that they had finished reading the text. Then a new screen appeared on which only two links pointing to unread nodes were presented. The participants had to click on a link to read the corresponding section. After that, the selected text was presented on the screen along with the link for announcing completion of the reading, but without any links. When only one node remained to be read, only one link corresponding to that text was presented for selection. After reading all the nodes, the participants had to perform a relatedness judgment task. They then had to answer 22 multiple-choice text-based questions and 10 multiple-choice inference questions, randomly mixed. Finally, the participants were asked about the criteria they had followed in selecting the links. For each selection made ( $n=25$ because the first and last texts could not be chosen), they were presented with the title of the text they had read before making the selection and with the two links available after reading that text (the selected link was signaled). For each selection, the participants had to indicate, from a series of reasons, why they had chosen that particular link. The reasons, which had been identified as the most common in the pilot experiments presented above, were (1) the link seemed the most interesting, (2) the link seemed the easiest, (3) the link seemed related to the previous text read, (4) the link was the one at the top, and (5) other reason (in this case, the participants had to write the criterion followed). They were restricted to report one reason per choice.

\section{Design}

A quasi-experimental design was used with reading strategy (see below) and prior knowledge (low vs. intermediate) as independent variables. The two levels of prior knowledge were defined according to the mean split of the answers to the eight multiple-choice questions about the participants' domain knowledge. The median score was 4 . Participants with scores of 4 or below $(n=36)$ were classified as having low knowledge $(M=2.9, S D=0.9)$, and those with scores above $4(n=35)$ were classified as having intermediate knowledge $(M=5.7, S D=0.9)$. The dependent variables were scores on inference questions, judgment ratings, and text-based questions. 


\section{Results \\ Analyses of Reading Strategies}

For both experiments, $p$ values less than .05 are considered significant unless otherwise noted. The participants' reading strategies were analyzed considering their declared criteria for link selection across the 25 selections. The participants were grouped under a particular reading strategy if they declared that they had selected a majority of links following that strategy. Three main strategies accounted for $93 \%$ of the participants: selecting the link at the top, selecting the most interesting link, and selecting the link related to the previous text (we will refer to these strategies as first mentioned, interest, and coherence, respectively). Four participants declared that they had selected the easiest links, and 1 that he or she made the selection randomly. Because they were so few in number, these 5 participants were excluded from the main analysis. The distribution of participants per condition can be seen in Table 2.

Interestingly, most of the participants declared that they had used more than one strategy during the experimental session. In Table 2, we present the percentage of times each criterion (interest, ease, coherence, top link, and other) was reported by each strategy group (first mentioned, interest, and coherence). The report of different criteria for each strategy group is particularly evident for the interest group, in which the participants declared that they had followed the interest link just $48 \%$ of the time. This result could challenge the validity of the procedure. In order to overcome this potential problem, in Experiment 2 we used a different procedure, instructing the participants to select the reading order following a given criterion (interest or coherence). To foreshadow, in Experiment 2 we did obtain an interest group with equivalent performance in reading order (i.e., mean LSA cosine) and in learning, which supports the classification made here. In addition, previous research supports the reliability and validity of the use of this retrospective debriefing methodology for the analysis of readers' strategies (Poulisse, Bongaerts, \& Kellerman, 1987). However, data obtained by this methodology should be validated against data from the reading process (Grotjahn, 1987; Taylor \& Dionne, 2000).

For this reason, we tested data from this grouping by declared strategy against three objective variables of link selection: the percentage of times a participant selected

Table 2

Criteria Followed for Link Selections (in Percentages), and Standard Deviations, as a Function of Strategy Group

Strategy Group

\begin{tabular}{|c|c|c|c|c|c|c|}
\hline \multirow[b]{3}{*}{ Criterion } & \\
\hline & \multicolumn{2}{|c|}{$\begin{array}{c}\text { First } \\
\text { Mentioned }\end{array}$} & \multicolumn{2}{|c|}{ Interest } & \multicolumn{2}{|c|}{ Coherence } \\
\hline & $\%$ & $S D$ & $\%$ & $S D$ & $\%$ & $S D$ \\
\hline Interest & 8.63 & 12.46 & 47.69 & 19.10 & 9.00 & 12.27 \\
\hline Ease & 3.16 & 6.34 & 18.31 & 16.09 & 3.67 & 6.45 \\
\hline Coherence & 2.11 & 6.31 & 22.92 & 16.22 & 81.33 & 19.90 \\
\hline Top link & 83.79 & 19.11 & 10.00 & 15.65 & 3.50 & 6.28 \\
\hline Other & 2.32 & 7.46 & 1.08 & 4.74 & 2.50 & 4.98 \\
\hline
\end{tabular}

the most coherent link, the percentage of times he or she selected the link at the top, and the mean time the participants spent deciding on reading order. The first ANOVA was conducted with reading strategy (first mentioned vs. interest vs. coherence) as the independent variable and mean LSA cosines as the dependent variable. Results revealed a significant difference between conditions $\left[F(2,63)=50.68, M S_{\mathrm{e}}=0.01\right]$. The participants in the coherence condition read the text in a more coherent order (mean LSA cosine $=0.52, S D=0.03$ ) than those in the interest $(M=0.46, S D=0.04)$ and linear $(M=$ $0.42, S D=0.02)$ conditions $[F(1,63)=96.27]$. The interest and linear conditions also differed significantly in the coherence of their transitions $[F(1,63)=4.38]$. In addition, results with percentage of top link selection as a dependent variable showed a significant difference between conditions $\left[F(2,63)=84.45, M S_{\mathrm{e}}=7.26\right]$. The participants in the first-mentioned condition selected the top link more often (mean percentage $=90.59, S D=10.32)$ than those in the interest $(M=57.50, S D=10.82)$ and coherence $(M=50.96, S D=11.07)$ conditions $[F(1,63)=$ 159.16]. The coherence and interest groups were marginally different for selection of the top link $[F(1,63)=3.56$, $p=.06]$. Finally, mean order decision time also differed for the three conditions $\left[F(2,63)=12.19, M S_{\mathrm{e}}=1.75\right]$. The participants in the first-mentioned condition spent less time deciding on reading order $(M=3.3 \mathrm{sec}, S D=1.1)$ than those in both the interest $(M=4.7, S D=1.7)$ and the coherence $(M=5.2, S D=1.1)$ conditions $[F(1,63)=$ 21.89]. The participants in the interest and coherence conditions did not differ in the time they spent deciding on reading order $[F(1,63)=1.25, p<.3]$. The three ANOVAs supported the grouping following the participants' declared strategies. The participants in the coherence condition differed from those in the interest condition mainly in that they selected the high-coherence link more often. In comparison, the participants following the first-mentioned criterion more often selected the top link and spent less time deciding which reading order to follow. From these results, it can be considered that the participants in the first-mentioned condition chose the reading order on the basis of a default screen position without actively analyzing the two provided links. For this reason, and following our theoretical exposition, we considered coherence and interest as the main strategies to explore in the comprehension analyses. This notwithstanding, we also analyzed the group in the first-mentioned condition as an ad hoc control group to explore possible differences between passive (i.e., first-mentioned) and active (i.e., coherence and interest) strategies. Learning differences between the active strategies and the first-mentioned strategy will favor the existence of a strategic component associated with the interest or coherence strategies.

\section{Comprehension Analyses}

Two ANOVAs were performed with reading strategy (interest vs. coherence) and prior knowledge (low vs. intermediate) as independent variables and the three comprehension measures (Pathfinder similarity values and 
scores on inference and text-based questions) and as dependent variables. Results are summarized in Table 3. No significant main effects were found for inference questions. However, the interaction between variables was significant $\left[F(1,42)=4.2, M S_{\mathrm{e}}=1.88\right]$. Supporting our hypotheses, simple effects analyses revealed significant differences for low knowledge: Low-knowledge participants following the coherence strategy scored higher than those following the interest strategy $[F(1,42)=4.73]$, but this was not the case for the intermediate-knowledge participants $(F<1)$. In addition, scores from participants following the first-mentioned strategy were compared to the scores from those following the two main strategies explored. Planned comparisons between strategies for each prior knowledge condition showed that the only significant difference was between the first-mentioned and coherence conditions for low-knowledge participants $[F(1,60)=$ 4.74, $\left.M S_{\mathrm{e}}=1.72\right]$. Low-knowledge participants following the coherence strategy scored higher than lowknowledge participants using the first-mentioned strategy.

A second ANOVA was conducted with Pathfinder similarity values as the dependent variable. Results showed a main effect of prior knowledge $\left[F(1,42)=9.78, M S_{\mathrm{e}}=\right.$ 0.01]. Participants with prior knowledge scored higher $(M=0.32, S D=0.09)$ than those without $(M=0.25$, $S D=0.07)$. In addition, the effect of strategy was nearly significant $\left[F(1,42)=3.47, M S_{\mathrm{e}}=0.01, p=.06\right]$. Participants following the coherence strategy seem to score higher $(M=0.31, S D=0.08)$ than those following the interest strategy $(M=0.25, S D=0.08)$. More importantly, results showed a significant interaction between variables $\left[F(1,42)=4.17, M S_{\mathrm{e}}=0.01\right]$. Supporting our hypotheses, simple effects analyses revealed a significant difference for the low-knowledge participants: Participants following the coherence strategy learned more than those using the interest strategy $[F(1,42)=7.74]$, but this was not the case for the intermediate-knowledge participants $(F<1)$. Again, scores from participants following the first-mentioned strategy were compared to scores from those following the two main strategies explored. As with the inference scores, planned comparisons between strategies for each knowledge condition showed only a nearly significant difference between the first-mentioned and coherence conditions for the low-knowledge participants
$\left[F(1,60)=3.59, M S_{\mathrm{e}}=0.01, p=.06\right]$. Low-knowledge participants following the coherence strategy seemed to score higher than low-knowledge participants following the first-mentioned strategy.

Finally, an ANOVA was conducted with scores on the text-based questions as the dependent variable. Results showed a main effect of prior knowledge $[F(1,42)=$ 5.01, $\left.M S_{\mathrm{e}}=9.41\right]$. Low-knowledge participants scored lower (mean percentage correct $=60.53, S D=15.52$ ) than intermediate-knowledge participants (mean percentage correct $=69.46, S D=12.20$ ). No other significant effects were found. Planned comparisons were made with the participants following the first-mentioned strategy included. The main effect of prior knowledge remained significant, but no other differences were found between strategies for either the low- or the intermediate-knowledge participants.

\section{Reading Time Analyses}

Additional analyses were conducted with strategy and prior knowledge included in order to assess the time spent reading the texts. The participants' reading times were measured in seconds per section. Reading time was then divided by the number of words in the section, yielding an average time spent on each word. Mean reading times were significantly different only for the strategy conditions $\left[F(2,60)=3.57, M S_{\mathrm{e}}=0.01\right]$. Participants in the firstmentioned condition spent less time reading the texts $(M=$ $0.21 \mathrm{sec} /$ word, $S D=0.06)$ than those in the coherence condition $(M=0.27 \mathrm{sec} /$ word, $S D=0.06)[F(1,60)=7.07]$, but they did not differ from participants in the interest condition $(M=0.25 \mathrm{sec} /$ word, $S D=0.09)[F(1,60)=2.63$, $p<.15]$. There were no differences between the coherence and interest conditions $(F<1)$.

\section{Discussion}

The data of Experiment 1 support the result from the pilot experiment that showed that coherence is not the only reading strategy followed by hypertext readers, as was suggested by the strategy competition model (Foltz, 1996; Goldman \& Saul, 1990). Thirty-eight percent of the participants reported that they had followed the coherence strategy, $27 \%$ reported following the interest strategy, and 28\% had chosen the link presented at the top. Therefore, coherence and interest can be considered as two main strategies followed

Table 3

Mean Comprehension Scores (and Standard Deviations) as a Function of Prior Knowledge and Strategy

\begin{tabular}{|c|c|c|c|c|c|c|c|c|c|c|c|c|}
\hline & \multicolumn{6}{|c|}{ Low Knowledge } & \multicolumn{6}{|c|}{ Intermediate Knowledge } \\
\hline & \multicolumn{2}{|c|}{$\begin{array}{c}\text { First } \\
\text { Mentioned }\end{array}$} & \multicolumn{2}{|c|}{ Interest } & \multicolumn{2}{|c|}{ Coherence } & \multicolumn{2}{|c|}{$\begin{array}{c}\text { First } \\
\text { Mentioned }\end{array}$} & \multicolumn{2}{|c|}{ Interest } & \multicolumn{2}{|c|}{ Coherence } \\
\hline & $M$ & $S D$ & $M$ & $S D$ & $M$ & $S D$ & $M$ & $S D$ & $M$ & $S D$ & $M$ & $S D$ \\
\hline Inference & 33.75 & 14.49 & 36.36 & 21.25 & 50.00 & 14.79 & 47.50 & 11.49 & 54.69 & 18.82 & 53.13 & 14.07 \\
\hline Text based & 59.55 & 13.80 & 57.02 & 16.68 & 64.05 & 14.15 & 61.82 & 8.07 & 67.61 & 11.51 & 71.31 & 12.72 \\
\hline Pathfinder $C$ & .24 & .05 & .20 & .04 & .29 & .07 & .30 & .05 & .32 & .08 & .33 & .10 \\
\hline$n$ & \multicolumn{2}{|c|}{10} & \multicolumn{2}{|c|}{11} & \multicolumn{2}{|c|}{11} & \multicolumn{2}{|c|}{10} & \multicolumn{2}{|c|}{8} & \multicolumn{2}{|c|}{16} \\
\hline
\end{tabular}

Note-Inference and text-based scores are reported in percentages of correct answers. Pathfinder $C$ similarity values are reported in ratings ranging from 0 to 1 . 
by hypertext readers (Ainley et al., 2002; Foltz, 1996). As we have already observed, the selection of a particular strategy can depend on characteristics of both hypertext and readers, so the identification of other important strategies and the features that lead a participant to follow a particular strategy is open to future research. In addition, the results support the hypothesis that reading strategies affect hypertext comprehension and that this effect interacts with the prior knowledge of the reader (Salmerón et al., 2005). On the one hand, low-knowledge readers' comprehension is higher when they select a text-coherent reading order than when they select the most interesting texts (Budd et al., 1995; Meyer \& Poon, 2001). On the other hand, for readers with some prior knowledge, comprehension is similar whether they follow the coherence strategy or the interest strategy. These results are supported by two situation model measures: scores on inference questions and relatedness judgment ratings. In addition, the same pattern of results is observed when the coherence and interest strategies are compared to nonactive selection of reading order (i.e., the first-mentioned strategy). For low-knowledge readers, the coherence strategy remains the best, and for intermediate-knowledge participants there is no difference between strategies. In addition, text-based results show no differences for reading strategies. This concurs with prior research on hypertext comprehension (Salmerón et al., 2005). The authors have found that the text reading order inherent to different reading strategies does not necessarily influence scores on text-based questions. On the contrary, they depend on the number of different sections of the hypertext that were read. In other words, a strategy that leads one to read a greater number of nodes increases scores on text-based questions (Salmerón et al., 2005; see also W. Kintsch \& Yarbrough, 1982). Because in Experiment 1 the participants had to read all the nodes, no differences for this variable were expected.

Results from the first-mentioned condition can be considered as a starting point in exploring the (strategic or text-induced) nature of the effects on comprehension of hypertext strategies. The logic for the comparisons is based on the fact that the first-mentioned condition lacks the active strategic feature associated with a reasoned selection of the reading order. Therefore, the fact that for intermediate-knowledge participants the interest strategy shows results similar to those of the first-mentioned strategy suggests that the effect of the interest strategy is based merely on the low-coherence reading order associated with it (i.e., it is a text-induced effect). This result is apparently contradictory to prior literature, which shows a strategic benefit of interest for intermediate-knowledge readers (Alexander et al., 1995; Garner \& Gillingham, 1991). Unfortunately, the first-mentioned condition does not allow one to distinguish between the text-induced and strategic effects of the coherence strategy because these effects differ not only on the strategic component but also on the reading order (low vs. high coherence). Therefore, a complete exploration of the nature of the effects of hy- pertext strategies must wait until the appropriate experimental conditions are considered in Experiment 2.

\section{EXPERIMENT 2}

The first objective of Experiment 2 was to replicate the effects found in Experiment 1 with a different methodology. In addition, in Experiment 2 we explored in depth the nature of the effects of hypertext reading strategies on comprehension. For this purpose, we included two nonstrategic conditions meant to isolate the potential strategic effects of the coherence and interest strategies. In one of these nonstrategic conditions, participants read (without choice of order) the text linearly presented in a highcoherence order, and in the other they read the text presented in a low-coherence order. Two comparisons were planned: the high-coherence nonstrategic condition versus the coherence condition, and the low-coherence nonstrategic condition versus the interest condition. In both comparisons, participants would read the text in the same order (high or low coherence, respectively), which would allow the text-induced effects to be controlled. Therefore, any difference found in these comparisons will support the existence of a strategic component associated with the fact that readers had to determine their own reading order (i.e., by choosing the interest or the coherence strategy). In addition to the hypotheses explored in Experiment 1, in Experiment 2 we considered two new hypotheses derived from the theoretical assumptions discussed in the introduction. First, according to the hypothesis of textinduced influence for low knowledge, participants with no prior knowledge who follow the coherence strategy learn equally to participants in the nonstrategic high-coherence order condition, and participants with no prior knowledge who use the interest strategy have learning outcomes similar to those of participants in the nonstrategic lowcoherence order condition. Second, according to the hypothesis of strategic influence for intermediate knowledge, participants with prior knowledge who follow the coherence strategy learn more than those following the nonstrategic high-coherence order condition, and participants with prior knowledge who follow the interest strategy achieve higher learning outcomes than those of the nonstrategic low-coherence order condition.

\section{Method}

Participants. One hundred fifty-two University of Colorado undergraduates participated for class credit. None of them had participated in Experiment 1.

Materials. For the reading strategy group, the materials were the same as those used in Experiment 1. For the nonstrategic group, two different text conditions were created: one in which the sections were ordered so that the coherence between transitions was as low as possible, and another in which the sections were ordered so that the coherence between transitions was as high as possible. This was done by arranging the sections in an order in which the sum of the LSA cosines between texts was the lowest and the highest possible, respectively. The comprehension tasks were the same as those used in Experiment 1. 
Procedure. The only change in the procedure was in the instructions provided to the participants. For the reading strategy group, the participants in the coherence condition were told to select the link that seemed more related to the content of the text immediately preceding it, whereas those in the interest condition were instructed to select the link that seemed more interesting. In the nonstrategic group, the participants were provided with only one link each time, so they were not able to choose the reading order. Instructions told them to select the link presented after reading each section.

Design. A between-groups design was used with reading strategy (interest vs. coherence) and prior knowledge (low vs. high) as independent variables. We established a nonstrategic condition for each reading strategy (i.e., low-coherence order for the interest strategy and high-coherence order for the coherence strategy). The two levels of prior knowledge were defined according to the median split of the answers to the eight questions about the participants' domain knowledge. The median score was 4 . Participants with scores of 4 or below $(n=89)$ were classified as having low knowledge $(M=3$, $S D=0.9)$, and those with scores greater than $4(n=63)$ were classified as having intermediate knowledge $(M=5.6, S D=0.9)$. The distribution of participants per condition is reported in Table 4 . The dependent variables were scores on inference questions, judgment ratings, and text-based questions.

\section{Results}

Analyses of reading strategies. To check the validity of the strategy instruction procedure used here, we compared the mean LSA cosines and order decision times in a strategic group (coherence vs. interest strategies) $\times$ prior knowledge (low vs. intermediate) interaction. Results revealed only a main effect of type of strategy $[F(1,72)=$ 54.23, $\left.M S_{\mathrm{e}}=0.01\right]$. As in Experiment 1, the participants in the coherence strategy condition read the text in a higher coherence order (mean LSA cosine $=0.52, S D=0.03$ ) than those in the interest strategy condition (mean LSA cosine $=0.46, S D=0.03$ ). In addition, the time participants spent selecting the reading order did not differ between conditions $\left[F(1,72)=2.69, M S_{\mathrm{e}}=3.34, p<.15\right.$ for the interaction]. Therefore, the reading strategy group (coherence and interest) was considered for the following analyses.

Comprehension analyses. Prior to considering our hypotheses, we analyzed comprehension outcomes from the nonstrategic group (low vs. high coherence) in order to check the results with prior research on the role of coherence order (Salmerón et al., 2005; Schnotz, 1982). For this purpose, we performed a set of ANOVAs with the nonstrategic group and prior knowledge (low vs. intermediate) as independent variables and the three compre- hension scores as dependent variables. Results from the inference questions revealed only a significant interaction $\left[F(1,72)=8.83, M S_{\mathrm{e}}=2.12\right]$. Supporting prior research, follow-up comparisons showed that low-knowledge readers tended to learn more with the high-coherence than with the low-coherence order $[F(1,72)=3.84, p=.05]$, whereas intermediate-knowledge readers showed the opposite pattern $[F(1,72)=5.05]$. Similar results were found for the Pathfinder similarities. Only the interaction between variables was significant $[F(1,72)=7.66$, $\left.M S_{\mathrm{e}}=0.01\right]$. Again, low-knowledge readers seemed to benefit more from the high- than from the low-coherence order $[F(1,72)=3.85, p=.05]$, whereas the opposite was found for intermediate-knowledge readers $[F(1,72)=$ 4.06]. There were no differences for the text-based questions ( $F<1$ for the interaction).

In order to assess hypotheses regarding the effect of strategies and prior knowledge on comprehension (i.e., those explored in Experiment 1), a set of ANOVAs was performed with strategy (coherence vs. interest) and prior knowledge (low vs. intermediate), using the different comprehension scores as the dependent variable (Table 4). Inference scores showed only an interaction between variables $\left[F(1,72)=4.48, M S_{\mathrm{e}}=1.67\right]$. Supporting our hypotheses, simple effects analyses revealed that low-knowledge participants in the coherence strategy condition outperformed those in the interest strategy condition $[F(1,72)=6.97]$, but this was not the case for intermediate-knowledge participants $(F<1)$. A similar pattern was found for the Pathfinder similarities. There was a main effect of prior knowledge $[F(1,72)=4.03$, $\left.M S_{\mathrm{e}}=0.01\right]$. Low-knowledge readers scored lower $(M=$ $0.27, S D=0.07)$ than intermediate-knowledge readers $(M=0.3, S D=0.07)$. There was no effect of strategy. However, the interaction between variables was significant $\left[F(1,72)=4.69, M S_{\mathrm{e}}=0.01\right]$. Again, simple effects analyses revealed that low-knowledge participants in the coherence strategy condition learned more than those in the interest strategy condition $[F(1,72)=5.68]$ but intermediate-knowledge participants did not $(F<1)$. No differences were found for the text-based questions ( $F<1$ for the interaction).

Finally, to assess hypotheses regarding the (strategic or text-induced) nature of the effects of reading strategies on comprehension, we conducted a series of planned com-

Table 4

Mean Comprehension Scores (in Percentages), and Standard Deviations, as a Function of Prior Knowledge and Strategy

\begin{tabular}{|c|c|c|c|c|c|c|c|c|c|c|c|c|c|c|c|c|}
\hline & \multicolumn{8}{|c|}{ Control } & \multicolumn{8}{|c|}{ Strategic } \\
\hline & \multicolumn{4}{|c|}{ LK } & \multicolumn{4}{|c|}{$\mathrm{IK}$} & \multicolumn{4}{|c|}{ LK } & \multicolumn{4}{|c|}{ IK } \\
\hline & \multicolumn{2}{|c|}{$\mathrm{LC}$} & \multicolumn{2}{|c|}{$\mathrm{HC}$} & \multicolumn{2}{|c|}{$\mathrm{LC}$} & \multicolumn{2}{|c|}{$\mathrm{HC}$} & \multicolumn{2}{|c|}{ Interest } & \multicolumn{2}{|c|}{ Coherence } & \multicolumn{2}{|c|}{ Interest } & \multicolumn{2}{|c|}{ Coherence } \\
\hline & $M$ & $S D$ & $M$ & $S D$ & $M$ & $S D$ & $M$ & $S D$ & $M$ & $S D$ & $M$ & $S D$ & $M$ & $S D$ & $M$ & $S D$ \\
\hline Inference & 41.76 & 20.97 & 53.42 & 20.75 & 52.38 & 28.79 & 34.29 & 10.53 & 37.82 & 14.23 & 53.42 & 17.35 & 53.06 & 23.54 & 50.48 & 16.08 \\
\hline Text based & 56.64 & 18.64 & 60.48 & 14.98 & 62.88 & 17.21 & 60.30 & 19.92 & 60.51 & 10.17 & 59.25 & 12.70 & 59.07 & 14.72 & 61.67 & 17.58 \\
\hline Pathfinder $C$ & .25 & .08 & .30 & .07 & .30 & .08 & \multirow{2}{*}{\multicolumn{2}{|c|}{$15^{.01}$}} & \multirow{2}{*}{\multicolumn{2}{|c|}{$17^{.00}$}} & .30 & .07 & .31 & .07 & .29 & .09 \\
\hline$n$ & \multicolumn{2}{|c|}{26} & \multicolumn{2}{|c|}{23} & \multicolumn{2}{|c|}{$12^{.00}$} & & & & & \multicolumn{2}{|c|}{23} & \multicolumn{2}{|c|}{21} & \multicolumn{2}{|c|}{15} \\
\hline
\end{tabular}

Note-Inference and text-based scores are reported as percentages of correct answers. Pathfinder $C$ similarity values are reported in ratings ranging from 0 to 1 . LK, low knowledge; IK, intermediate knowledge; LC, low coherence; HC, high coherence. 
parisons (Rosenthal \& Rosnow, 1985). For each strategy (interest and coherence) and each level of prior knowledge (low and intermediate), we made a comparison with its corresponding nonstrategic condition (low and high coherence, respectively). If a comparison failed to reveal differences, we could assume that the comprehension effect of a particular strategy is due mainly to the text-induced effect of reading order (as predicted for low-knowledge readers). By contrast, if a comparison did reveal a significant difference, it would support the claim that the comprehension effect for that particular strategy is independent of that induced by reading order (as predicted for intermediateknowledge readers). In support of Hypothesis 1 (textinduced influence for low knowledge), no comparison was significant for low-knowledge readers $(F \mathrm{~s}<1$ for both interest and coherence strategies and for both dependent variables: inference and Pathfinder scores). Similarly, no differences were found in the comparisons for the interest strategy for intermediate-knowledge readers $(F \mathrm{~s}<1$ for both inference and Pathfinder scores). However, in support of Hypothesis 2 (strategic influence for intermediate knowledge), planned comparisons showed a significant difference for the coherence strategy for intermediateknowledge readers $\left[F(1,144)=5.08, M S_{\mathrm{e}}=1.89\right.$ for inference scores and $F(1,144)=4.01, M S_{\mathrm{e}}=0.01$ for Pathfinder similarities]. The intermediate-knowledge participants following the coherence strategy learned more than those performing linear reading of a high-coherence ordered text without link selection (Figures 1 and 2).

Reading time analyses. A possible influence of reading times was explored for the strategic and nonstrategic groups by prior knowledge. The participants' reading times were measured in seconds per section. Reading time was then divided by the number of words in the section, yielding an average time spent on each word. None of the effects was significantly reliable ( $F<1$ for the three-way interaction).

\section{Discussion}

Results from Experiment 2 replicate the main effects found in Experiment 1 using a different experimental methodology. Low-knowledge readers learn more by following the coherence strategy than by using the interest strategy. In contrast, intermediate-knowledge readers learn equally from both strategies. In addition, the results of Experiment 2 allow us to clarify the nature of the comprehension effects of the different strategies. Comprehension for low-knowledge readers following the coherence or interest strategy is similar to comprehension of those following a high- or low-coherence order without link selection. Therefore, for novice readers the effect of reading strategies seems to be based merely on their indirect effect on text order coherence (Salmerón et al., 2005; Schnotz, 1982).

For readers with some prior knowledge, the results of Experiment 2 show a strategic effect for the coherence strategy but fail to show a similar effect for the interest strategy. ${ }^{3}$ Intermediate-knowledge participants instructed to follow the coherence strategy learned more than those reading the text in a high-coherence order without link selection. This effect is consistent with the literature of coherence and prior knowledge. On the one hand, when readers with intermediate knowledge read a high-coherence text they do not need to engage in deep processing in order to understand the text, and, as a consequence, their learning will drop in comparison with when they read a more challenging text (e.g., a low-coherence text; McNamara, 2001; McNamara et al., 1996; McNamara \& Kintsch, 1996). This seems to be the case for the condition in which a (nonstrategic) high-coherence order text without link selection is read. On the other hand, when readers with some prior knowledge are instructed to process the text actively, they can overcome the otherwise shallow processing induced by a high-coherence text (E. Kintsch \& W. Kintsch, 1995;

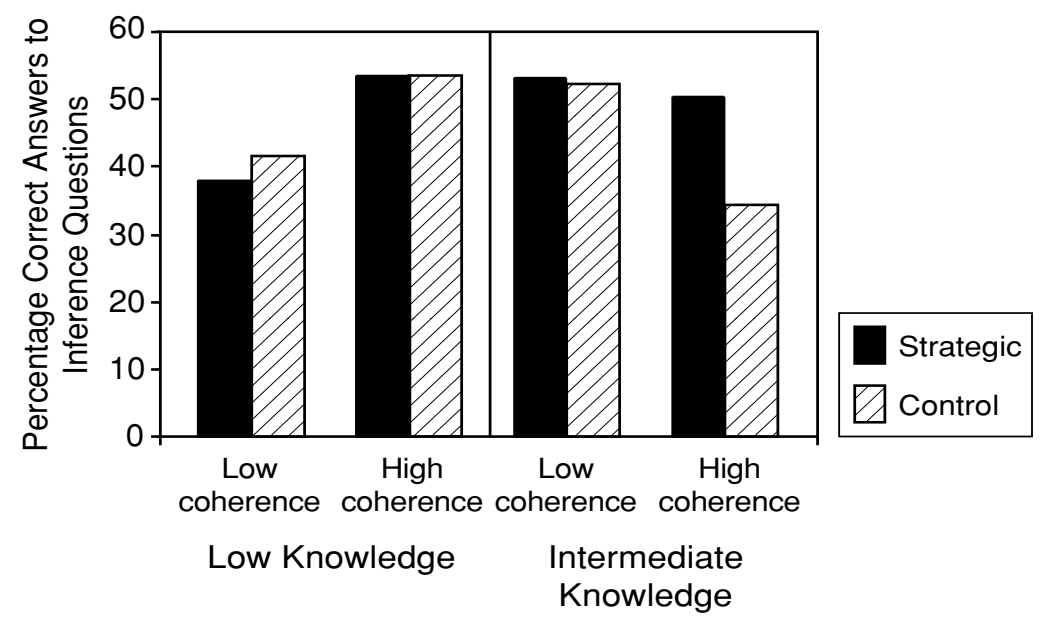

Figure 1. Percentage of correct answers to inference questions as a function of type of task, prior knowledge, and text order coherence. 


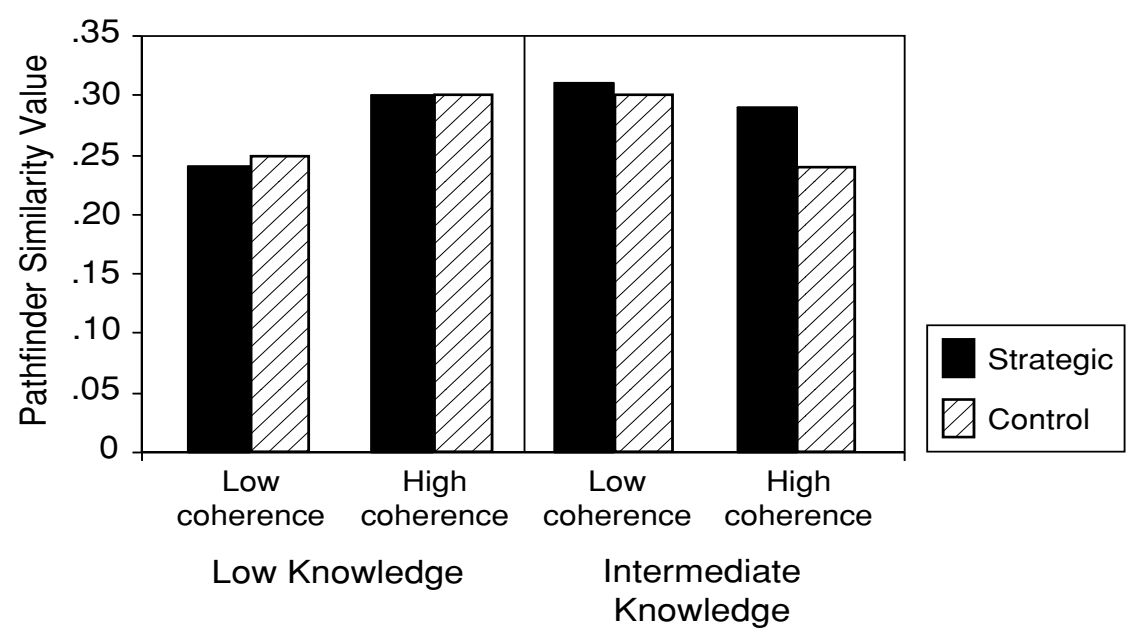

Figure 2. Judgment relatedness scores (expressed as Pathfinder similarity values) as a function of type of task, prior knowledge, and text order coherence.

McNamara, 2001). Participants in the coherence strategy condition read the text in a high-coherence order, but the selection of the highly related text induces them to engage in more active processing of the text. By contrast, the participants of Experiment 2 who were instructed to follow the interest strategy comprehended the text at the same level as those who read the text in a low-coherence order without link selection. This result fails to support the claim that interest improves comprehension for intermediateknowledge readers (Alexander et al., 1995; Garner \& Gillingham, 1991). However, a closer look at the mechanisms by which people with intermediate knowledge comprehend a text can help to clarify these apparently contradictory results. Readers with some prior knowledge will improve their comprehension by activating their existing knowledge and linking it to the ideas expressed in the text (W. Kintsch, 1994). Therefore, the critical issue is to evaluate the situations in which intermediate readers process a text actively independent of whether this activation comes from the text (e.g., low-coherence text) or from the strategy (e.g., high reading skills, coherence strategy). For example, in concurrence with the present findings, O'Reilly and McNamara (in press) found that readers with some prior knowledge can overcome the negative effects of a high-coherence text if they possess high reading skills. In our case, activation of the participants in the nonstrategic low-coherence order condition was induced by the need to clarify the coherence breaks in the text. In addition, activation of participants selecting the interesting link could come from the coherence breaks (LSA cosines for reading order are significantly lower for this strategy than for the coherence strategy), the induced interest of the topic (Hidi, 1990, 1995; McDaniel et al., 2000), or a combination of both.

Unfortunately, for the interest strategy it is hard to isolate text-induced and strategic effects. For that purpose, we need to control for the coherence order effects - that is, we need to design a condition in which participants are instructed to select the most interesting parts first (interest strategy) and which simultaneously presents the different parts in a high-coherence order. This procedure seems implausible because text coherence is a property of the text, but text interest depends on the participant. We can, however, positively conclude that the interest strategy promotes learning for intermediate-knowledge participants at the same level as the coherence strategy does.

\section{CONCLUSIONS}

In two experiments, we examined the relation between prior knowledge and reading strategies in learning from hypertext. In the following, we summarize the results that provided clear insights into this relation. We then discuss some possible interrelations between the coherence and the interest strategies. Finally, we discuss our results in an attempt to resolve inconsistencies in the literature concerning whether hypertext supports better comprehension than traditional linear texts.

\section{Reading Strategies, Prior Knowledge, and Hypertext Learning}

Results from two experiments support the claim that hypertext readers follow different criteria in selecting the reading order of the text and that these have distinct effects on comprehension depending on the reader's prior knowledge. The two main criteria consist in selecting the link semantically related to the link previously read (Foltz, 1996) and in choosing the most interesting links, delaying selection of the less interesting links (Ainley et al., 2002). A third criterion consists in the selection of the link based on a default screen position. For low-knowledge readers, the coherence strategy supported better learning of the text (Meyer \& Poon, 2001). The nature of this effect seems to rely on the improvement of text order coherence induced by this strategy. By contrast, for intermediate-knowledge readers both the coherence strategy and the interest strat- 
egy benefited comprehension equally. In the case of the coherence strategy, this benefit was supported through the active processing induced by the selection of the highcoherence links. In the case of the interest strategy, the learning benefit could be associated with the combined effects of an increase in the automatic attention devoted to the comprehension process (Hidi, 1990, 1995; McDaniel et al., 2000) and the coherence breaks in the induced reading order as a result of the strategy.

\section{Relation Between Coherence and Interest Strategies}

In this work, we have assumed that the coherence and interest strategies are independent, but this assumption requires some consideration. For example, a reader mainly selecting the high-coherence link might sometimes also be selecting the most interesting link, or a reader mainly selecting the most interesting link might sometimes also simultaneously select a link with argument overlap (even though the reader is not aware of the semantic relation). This overlap between the coherence and interest strategies is possible due to their different natures: Whereas coherence is a feature of the text, interest depends on the reader. We should also consider the possible interdependence between the two strategies. As was described in the introduction, interest in a title node can be both individual (i.e., permanent) and situational (i.e., text induced). Individual interest depends on the reader's affinities and therefore is independent of text coherence. However, situational interest in a title node can be influenced by some features of the text, including text coherence (Schraw, 1997; Schraw, Bruning, \& Svoboda, 1995). Schraw and colleagues found that reported situational interest in a text was positively correlated with reported ease of processing of the same text. Unfortunately, no experimental manipulation of text coherence was done, so the direction of the relation is tentative. In our context, these results could suggest either that participants selecting the high-coherence link will also develop some situational interest in the title node, or participants selecting the most interesting link will sometimes select the node that most enhances text coherence. Therefore, the important question here is to evaluate to what extent this issue limits the validity of the procedure and the theoretical implications of our experiments. In Experiment 1, the participants reported the criterion they followed for each of the 25 selections between nodes. We cannot know if they simultaneously considered both coherence and interest in making their choices because they were restricted to report only one criterion per choice. However, in Experiment 2 the readers were instructed to follow either the most coherent link or the most interesting link. Therefore, if either coherence promoted interest or vice versa, the participants in both conditions should have followed similar reading orders. Contrary to that prediction, the participants in the coherence condition read the text in a more coherent order than did those in the interest condition (as measured by the LSA cosine between texts transited). Therefore, although we agree that coherence and interest strategies can overlap to some extent, we also believe that results from reading order measures and learning performance (e.g., differences between strategies for low-knowledge readers) support our claim that both strategies affect hypertext comprehension independently.

\section{Is Hypertext a Good Alternative to Linear Texts for Promoting Learning?}

The results from both experiments can also be considered in order to explore the benefits and drawbacks of hypertext and linear text. It should be noted that we restrict our analysis to a main feature of hypertext - namely, the selection of reading order. Early proposals in the literature of hypertext comprehension claimed that hypertext could improve learning more than a linear version of the text. The rationale was that mapping the semantic structure of the text onto the hypertext links would result in greater improvement in the reader's mental representation of the text (see, e.g., Jonassen, 1993; McDonald, Paap, \& McDonald, 1990). However, more than a decade of research has failed to support this claim (Dillon \& Gabbard, 1998; Unz \& Hesse, 1999). The distinction proposed here between the strategic and the text-induced effects of reading strategies in hypertext can be useful for determining when a hypertext can be more helpful than a linear text: If there is a strategic effect associated to the selection of reading order, it could be concluded that hypertext would be beneficial. Overall, results support the claim that hypertext can be beneficial for readers with prior knowledge, particularly when they are induced to actively select the reading order (e.g., by using links embedded in the text instead of explicit overviews of its content). This benefit is related to the processes by which readers with prior knowledge comprehend a text. When they engage in active processing, they are able to use their prior knowledge to construct a more coherent representation of the text (E. Kintsch \& W. Kintsch, 1995; W. Kintsch, 1994; McNamara, 2001). However, it should be noted that readers with prior knowledge will learn equally from a hypertext and from a linear text if they process the text actively. In addition, results reveal that hypertext is not particularly beneficial for low-knowledge readers. This is due to the fact that for low-knowledge readers the selection order does not affect comprehension strategically, but rather indirectly, through the changes in the coherence of the reading order associated with a particular strategy. In the best scenario, low-knowledge readers who select the order while trying to establish global text coherence will learn equally to those who read a high-coherence version of the text linearly. However, when choosing one of the other particular strategies for order selection (i.e., interest or screen position), breaks in text coherence would hamper their comprehension (Charney, 1994; Fritz, 1999). Therefore, a critical issue for low-knowledge readers using a hypertext as a way of learning is to identify what makes a reader select the order in a coherent manner. A possible explanation may be related to reading monitoring skills (see, e.g., Roberts \& Newton, 2001). When a reader decides to choose the links following a strategy that induces breaks in text coherence (e.g., interest or screen position), 
he or she would experience comprehension problems that ultimately could lead him or her to switch to the coherence strategy. However, in order to do that, the reader must realize that his or her comprehension of the text presented in the hypertext is not optimal, a phenomenon that can be related to his or her monitoring skills (Bannert, 2003; Hill \& Hannafin, 1997; Schmidt \& Ford, 2003). Therefore, it could be argued that low-knowledge readers with good monitoring skills will tend to avoid strategies that induce breaks in text coherence.

\section{REFERENCES}

Acton, W. H., Johnson, P. J., \& Goldsmith, T. E. (1994). Structural knowledge assessment: Comparison of referent structures. Journal of Educational Psychology, 86, 303-311.

Ainley, M., Hidi, S., \& BerndorfF, D. (2002). Interest, learning, and the psychological processes that mediate their relationship. Journal of Educational Psychology, 94, 545-561.

Alexander, P. A., Jetton, T. L., \& Kulikowich, J. M. (1995). Interrelationship of knowledge, interest, and recall: Assessing a model of domain learning. Journal of Educational Psychology, 87, 559-575.

Alexander, P. A., Kulikowich, J. M., \& Schulze, S. K. (1994). How subject-matter knowledge affects recall and interest. American Educational Research Journal, 31, 313-337.

Anderson-InMan, L., \& Horney, M. A. (1994). The electrotext project: Hypertext reading patterns of middle school students. Journal of Educational Multimedia \& Hypermedia, 3, 71-91.

BANNERT, M. (2003). Effekte metakognitiver Lernhilfen auf den Wissenserwerb in vernetzten Lernumgebungen [Effects of metacognitive help on knowledge acquisition in Web-based learning environments]. Zeitschrift für Pädagogische Psychologie, 17, 13-25.

Barab, S. A., Bowdish, B. E., \& Lawless, K. A. (1997). Hypermedia navigation: Profiles of hypermedia users. Educational Technology Research \& Development, 45, 23-42.

Barab, S. A., Bowdish, B. E., Young, M. F, \& Owen, S. V. (1996). Understanding kiosk navigation: Using log files to capture hypermedia searches. Instructional Science, 24, 377-395.

Barab, S. A., Fajen, B. R., Kulikowich, J. M., \& Young, M. F. (1996). Assessing hypertext navigation through Pathfinder: Prospects and limitations. Journal of Educational Computing Research, 15, 185-205.

Barab, S. A., Young, M. F., \& WANG, J. (1999). The effects of navigational and generative activities in hypertext learning on problem solving and comprehension. International Journal of Instructional Media, 26, 283-309.

Britt, M. A., Rouet, J.-F., \& Perfetti, C. A. (1996). Using hypertext to study and reason about historical evidence. In J.-F. Rouet, J. J. Levonen, A. Dillon, \& R. J. Spiro (Eds.), Hypertext and cognition (pp. 43-72). Mahwah, NJ: Erlbaum.

BRITTON, B. K., \& GÜLGÖZ, S. (1991). Using Kintsch's computational model to improve instructional text: Effects of inference calls on recall and cognitive structures. Journal of Educational Psychology, 83, 329-345.

BudD, D., Whitney, P., \& TuRley, K. J. (1995). Individual differences in working memory strategies for reading expository text. Memory \& Cognition, 23, 735-748.

Charney, D. (1994). The impact of hypertext on processes of reading and writing. In S. J. Hilligoss \& C. L. Selfe (Eds.), Literacy and computers (pp. 238-263). New York: Modern Language Association.

Chi, M. T. H., Bassok, M., Lewis, M. W., Reimann, R., \& Glaser, R. (1989). Self-explanation: How students study and use examples in learning to solve problems. Cognitive Science, 13, 145-182.

Chi, M. T. H., De Leeuw, M., Chiu, M., \& LaVancher, C. (1994). Eliciting self-explanations improves understanding. Cognitive Science, 18, 439-477.

DANNER, F. W. (1976). Children's understanding of intersentence organization in the recall of short descriptive passages. Journal of Educational Psychology, 68, 174-183.
Dearholt, D. W., \& Schvaneveldt, R. W. (1990). Properties of pathfinder networks. In R. W. Schvaneveldt (Ed.), Pathfinder associative networks: Studies in knowledge organization (pp. 1-30). Norwood, NJ: Ablex.

Dillon, A. (1991). Readers' models of text structures: The case of academic articles. International Journal of Man-Machine Studies, 35, 913-925.

Dillon, A., \& GabBard, R. (1998). Hypermedia as an educational technology: A review of the quantitative research literature on learner comprehension, control, and style. Review of Educational Research, 68, 322-349.

Foltz, P. W. (1996). Comprehension, coherence, and strategies in hypertext and linear text. In J.-F. Rouet, J. J. Levonen, A. Dillon, \& R. J. Spiro (Eds.), Hypertext and cognition (pp. 109-136). Mahwah, NJ: Erlbaum.

Foltz, P. W., Kintsch, W., \& Landauer, T. K. (1998). The measurement of textual coherence with latent semantic analysis. Discourse Processes, 25, 285-307.

Fritz, G. (1999). Coherence in hypertext. In W. Bublitz, U. Lenk, \& E. Ventola (Eds.), Coherence in spoken and written discourse: How to create it and how to describe it (pp. 221-232). Amsterdam: John Benjamins.

Garner, R., Alexander, P. A., Gillingham, M., Kulikowich, J. M., \& Brown, R. (1991). Interest and learning from text. American Educational Research Journal, 28, 643-659.

Garner, R., \& Gillingham, M. (1991). Topic knowledge, cognitive interest, and text recall: A microanalysis. Journal of Experimental Education, 59, 310-319.

Goldman, S. R., \& Saul, E. (1990). Flexibility in text processing: A strategy competition model. Learning \& Individual Differences, 2, 181-219.

Goldman, S. R., Saul, E., \& Coté, N. (1995). Paragraphing, reader, and task effects on discourse comprehension. Discourse Processes, 20, 273-305.

Goldsmith, T. E., Johnson, P. J., \& Acton, W. H. (1991). Assessing structural knowledge. Journal of Educational Psychology, 83, 88-96.

Grotjahn, R. (1987). On the methodological basis of introspective methods. In C. Faerch \& G. Kasper (Eds.), Introspection in second language research (pp. 54-81). Philadelphia: Multilingual Matters.

HiDI, S. (1990). Interest and its contribution as a mental resource for learning. Review of Educational Research, 60, 549-571.

HidI, S. (1995). A re-examination of the role of attention in learning from text. Educational Psychology Review, 7, 323-350.

HIDI, S. (2001). Interest, reading, and learning: Theoretical and practical considerations. Educational Psychology Review, 13, 191-209.

Hill, J. R., \& HannAfin, M. J. (1997). Cognitive strategies and learning from the World Wide Web. Educational Technology Research \& Development, 45, 37-64.

Horney, M. A., \& ANDERSON-InMan, L. (1994). The electrotext project: Hypertext reading patterns of middle school students. Journal of Educational Multimedia \& Hypermedia, 3, 71-91.

JoNASSEN, D. H. (1993). Effects of semantically structured hypertext knowledge bases on users' knowledge structures. In C. McKnight, A. Dillon, \& J. Richardson (Eds.), Hypertext: A psychological perspective (pp. 153-168). New York: Horwood.

KINTSCH, E., \& KinTSCH, W. (1995). Strategies to promote active learning from text: Individual differences in background knowledge. Swiss Journal of Psychology, 54, 141-151.

KINTSCH, W. (1980). Learning from text, levels of comprehension, or: Why anyone would read a story anyway. Poetics, 9, 87-98.

KInTSCH, W. (1988). The role of knowledge in discourse comprehension: A construction-integration model. Psychological Review, 95, 163-182.

KINTSCH, W. (1994). Text comprehension, memory, and learning. American Psychologist, 49, 294-303.

Kintsch, W. (1998). Comprehension: A paradigm for cognition. New York: Cambridge University Press.

KINTSCH, W. (2002). On the notions of theme and topic in psychological process models of text comprehension. In M. Louwerse \& V. Peer, Thematics: Interdisciplinary studies (pp. 157-170). Amsterdam: John Benjamins. 
Kintsch, W., \& YARBrough, J. C. (1982). The role of rhetorical structure in text comprehension. Journal of Educational Psychology, 74, 828-834.

Lawless, K. A., Brown, S. W., Mills, R., \& Mayall, H. J. (2003). Knowledge, interest, recall and navigation: A look at hypertext processing. Journal of Literacy Research, 35, 911-934.

LAWLESS, K. A., \& KuliKowich, J. M. (1996). Understanding hypertext navigation through cluster analysis. Journal of Educational Computing Research, 14, 385-399.

Lawless, K. A., \& Kulikowich, J. M. (1998). Domain knowledge, interest, and hypertext navigation: A study of individual differences. Journal of Educational Multimedia \& Hypermedia, 7, 51-70.

Lawless, K. A., Mills, R., \& Brown, S. W. (2002). Children's hypermedia navigational strategies. Journal of Research on Computing in Education, 34, 274-284.

LODEWIJKs, H. (1982). Self-regulated versus teacher-provided sequencing of information in learning from text. In A. Flammer \& W. Kintsch (Eds.), Discourse processing (pp. 509-520). Amsterdam: NorthHolland.

Magliano, J. P., Trabasso, T., \& Graesser, A. C. (1999). Strategic processing during comprehension. Journal of Educational Psychology, 91, 615-629.

MaYer, R. E. (1976). Some conditions of meaningful learning for computer programming: Advance organizers and subject control of frame order. Journal of Educational Psychology, 68, 143-150.

McDaniel, M. A., Waddill, P. J., Finstad, K., \& Bourg, T. (2000). The effects of text-based interest on attention and recall. Journal of Educational Psychology, 92, 492-502.

McDonald, J. E., PaAp, K. R., \& McDonald, D. R. (1990). Hypertext perspectives: Using Pathfinder to build hypertext systems. In R. W. Schvaneveldt (Ed.), Pathfinder associative networks: Studies in knowledge organization (pp. 197-212). Norwood, NJ: Ablex.

McNamara, D. S. (2001). Reading both high-coherence and lowcoherence texts: Effects of text sequence and prior knowledge. Canadian Journal of Experimental Psychology, 55, 51-62.

McNAmAra, D. S. (2004). SERT: Self-explanation reading training. Discourse Processes, 38, 1-30.

McNamara, D. S., Kintsch, E., Songer, N., \& Kintsch, W. (1996). Are good texts always better? Interaction of text coherence, background knowledge, and levels of understanding in learning from text. Cognition \& Instruction, 14, 1-42.

McNamaRa, D. S., \& KinTsCH, W. (1996). Learning from text: Effect of prior knowledge and text coherence. Discourse Processes, 22, 247 288.

McNamara, D. S., \& ScotT, J. L. (1999). Training reading strategies. In Proceedings of the Twenty-first Annual Meeting of the Cognitive Science Society (pp. 387-392). Hillsdale, NJ: Erlbaum.

Meyer, B., \& PoON, L. W. (2001). Effects of structure strategy training and signaling on recall of text. Journal of Educational Psychology, 93, 141-159.

Niederhauser, D. S., Reynolds, R. E., Salmen, D. J., \& Skolmoski, P. (2000). The influence of cognitive load on learning from hypertext. Journal of Educational Computing Research, 23, 237-255.

O'Reilly, T., \& McNamara, D. S. (in press). Good texts can be better for skilled comprehenders. Discourse Processes.

Poulisse, N., Bongaerts, T., \& Kellerman, E. (1987). The use of retrospective verbal reports in the analysis of compensatory strategies. In C. Faerch \& G. Kasper (Eds.), Introspection in second language research (pp. 213-299). Philadelphia: Multilingual Matters.

Pressley, M., Symons, S., McDaniel, M. A., Snyder, B. L., \& TurNURE, J. E. (1988). Elaborative interrogation facilitates acquisition of confusing facts. Journal of Educational Psychology, 80, 268-278.

Roberts, M. J., \& Newton, E. J. (2001). Understanding strategy selection. International Journal of Human-Computer Studies, 54, 137-154.

Rosenthal, R., \& Rosnow, R. L. (1985). Contrast analysis: Focused comparisons in the analysis of variance. New York: Cambridge University Press.

Rouet, J.-L., Favart, M., Britt, M. A., \& Perfetti, C. A. (1997). Studying and using multiple documents in history: Effects of discipline expertise. Cognition \& Instruction, 15, 85-106.

Salmerón, L., Cañas, J. J., Kintsch, W., \& Fajardo, I. (2005). Read- ing strategies and hypertext comprehension. Discourse Processes, 40, 171-191.

SchmidT, A. M., \& FoRD, J. K. (2003). Learning within a learner control training environment: The interactive effects of goal orientation and metacognitive instruction on learning outcomes. Personnel Psychology, 56, 405-429.

Schnotz, W. (1982). How do different readers learn with different text organizations? In A. Flammer \& W. Kintsch (Eds.), Discourse processing (pp. 87-97). Amsterdam: North-Holland.

Schnotz, W. (1984). Comparative instructional text organization. In H. Mandl, N. L. Stein, \& T. Trabasso (Eds.), Learning and comprehension of text (pp. 53-81). Hillsdale, NJ: Erlbaum.

ScHNotz, W. (1993). Adaptive construction of mental representations in understanding expository texts. Contemporary Educational Psychology, 18, 114-120.

ScHraw, G. (1997). Situational interest in literary text. Contemporary Educational Psychology, 22, 436-456.

Schraw, G., Bruning, R., \& Svoboda, C. (1995). Sources of situational interest. Journal of Reading Behavior, 27, 1-17.

ScHVANEVELDT, R. (ED.) (1990). Pathfinder associative networks: Studies in knowledge organization. Norwood, NJ: Ablex.

TAYLOR, K. L., \& DiOnNe, J. P. (2000). Accessing problem-solving strategy knowledge: The complementary use of concurrent verbal protocols and retrospective debriefing. Journal of Educational Psychology, 92, 413-425.

Tobias, S. (1994). Interest, prior knowledge, and learning. Review of Educational Research, 64, 37-54.

Trabasso, T., \& Magliano, J. P. (1996). Conscious understanding during text comprehension. Discourse Processes, 21, 255-288.

Unz, D. C., \& Hesse, F. W. (1999). The use of hypertext for learning. Journal of Educational Computing Research, 20, 279-295.

VAN DiJK, T. A., \& KINTSCH, W. (1983). Strategies of discourse comprehension. New York: Academic Press.

Wade, S. E., Buxton, W. M., \& Kelly, M. (1999). Using think-alouds to examine reader-text interest. Reading Research Quarterly, 34, 194-216.

WAGNER, R. K., \& Sternberg, R. J. (1987). Executive control in reading comprehension. In B. K. Britton \& S. M. Glynn (Eds.), Executive control processes in reading. Hillsdale, NJ: Erlbaum.

WALKER, W. H. (1981). Interest as a function of knowledge (Tech. Rep. No. 109). Boulder, CO: University of Colorado, Institute of Cognitive Science.

\section{NOTES}

1. For example, imagine that a reader has just read a hypertext section titled "Effects of Sunlight on Air Quality" and that he or she has to decide which of the following two sections of the same hypertext to read next: "Effects of Meteorology on Air Quality" or "Negative Effects of Climate Change on Human Health." Imagine that the reader has a strong interest on topics related to health (e.g., because he or she is a health sciences student). If the reader follows the coherence strategy, he or she would probably choose the section on the related topic of air quality. However, if the interest strategy is followed, the reader would probably pick the section related to human health. In this case, by following the interest strategy the reader would be faced with a coherence break in the reading order.

2. Because the effect of prior knowledge in comprehension is a linear function and the effect of interest and knowledge can follow a U-shaped function (but see Tobias, 1994, for arguments favoring a linear relation), we can consider that intermediate-knowledge readers benefit from both effects. In addition, because in our experiments we used an atmosphere science text with psychology undergraduate students, we assume that participants with higher scores on a prior knowledge questionnaire are in fact intermediate-knowledge readers, not experts.

3. An alternative explanation for the null effects between the coherence and interest strategies for intermediate-knowledge readers is that these readers simply had less to learn from the text because they knew more at the beginning of the study. However, this explanation has two drawbacks. First, prior knowledge was measured in both experiments with a text covering basic issues of the topic of the study text, rather than including more specific content of the study text itself. Therefore, as in 
most experiments using the prior knowledge manipulation, we assume that intermediate-knowledge readers know some basics of the text topic, but not the details of it. Second, for intermediate-knowledge readers there are differences between conditions that cannot be explained by this interpretation. Concretely, intermediate-knowledge readers learned less when they read a high-coherence ordered text without node selection (i.e., the nonstrategic high-coherence condition of Experiment 2) than they did in the other conditions.

\section{APPENDIX \\ Sample Questions}

\section{Prior Knowledge Question}

The Montreal Protocol is accepted by nations agreeing to restrict the release of

A. ozone-depleting chemicals. (correct)

B. greenhouse gases.

C. climate-change chemicals.

\section{Text-Based Question}

Human activity especially affects

A. the four layers of the atmosphere.

B. the two layers of the atmosphere closest to the earth's surface. (correct)

C. the two intermediate layers of the atmosphere.

The answer to this question appeared in the following paragraph of a node:

The atmosphere consists of a relatively narrow shell of air encircling the earth that supports animal and plant life. Human activity especially affects the two layers of the atmosphere closest to the earth's surface: the troposphere, which extends from the surface to about 12 miles, and the stratosphere, which extends from 12 miles up to approximately 30 miles. These portions of the atmosphere are critical in regulating our climate.

\section{Inference Question}

Ozone in the higher and lower levels of the atmosphere ...

A. are chemically different.

B. differ greatly in their environmental effects. (correct)

C. can cause skin cancer.

To answer this question, participants had to relate information contained in the following three different nodes.

1. Ozone is a naturally occurring gas molecule containing three atoms of oxygen. It is mainly found in two parts of the atmosphere: Most (about 90\%) resides in the upper atmosphere or stratosphere, where it forms the stratospheric ozone layer; the remaining ozone, referred to as ground level ozone or tropospheric ozone, is present in the lower region of the atmosphere.

2. A range of negative environmental and human health impacts associated with ozone depletion can be identified, although their exact nature is difficult to quantify. Known effects include increased incidence of skin cancers and eye disorders (e.g., cataracts), damage to the immune system, and adverse effects on plant development and phytoplankton growth.

3. Observed effects of ground-level ozone on human health include irritation of the eyes and air passages, damage to the mechanisms that protect the human respiratory tract, and, for some asthma sufferers, increased sensitivity of the airways to allergic triggers.

(Manuscript received October 7, 2004;

revision accepted for publication June 10, 2005.) 